http://jmscr.igmpublication.org/home/

ISSN (e)-2347-176x ISSN (p) 2455-0450

crossref DOI: https://dx.doi.org/10.18535/jmscr/v7i7.112

Journal Of Medical Science And Clinical Research

\title{
Dilated Cardiomyopathy: Aetiology, Clinical Presentation, ECG and Echo Cardiographic Evaluations Our Experience in a Tertiary Care Hospital
}

\author{
Authors \\ Dr Nirmal Kumar Mohanty ${ }^{1}$, Dr Bijaya Kumar Dash ${ }^{2^{*}}$, Dr Chhabi Satpathy ${ }^{3}$, \\ Dr S.N.Routray ${ }^{4}$ \\ ${ }^{1}$ Associate Prof., Department of Cardiology, S.C.B. Medical College, Cuttack \\ ${ }^{2}$ Assistant Professor, SCB Medical College, Deptt of cardiology Cuttack \\ ${ }^{3}$ Associate Professor, Deptt of cardiology. SCB Medical College Cuttack \\ ${ }^{4}$ Professor of Cardiology, SCB Medical College, Cuttack \\ *Corresponding Author \\ Dr Bijaya Kumar Dash \\ Assistant Professor, SCB Medical College, Deptt of cardiology Cuttack
}

\begin{abstract}
Background: Dilated cardiomyopathy refers to a group of heterogenous myocardial disorders characterized by ventricular dilation and depressed myocardial contractility in the absence of abnormal loading conditions i.e. hypertension and valvular heart disease.
\end{abstract}

Aims \& Objectives: To study the clinical profile ECG and echocardiographic abnormalities and to determine the aetiology of dilated cardiomyopathy.

Study Design:Prospective cross sectional observational study.

Material \& Methods: Fifty newly diagnosed cases of dilated cardiomyopathy admitted to the department of cardiology of SCB Medical College, Cuttack over a period of one year from 01.04.2017 to 30.03.2018 were evaluated clinically and with ECG and echocardiography.

Statistical Analysis: Was done with percentage proportions, chi square test and corrections. The level of significance was set at $P<0.05$.

Results: Dilated cardiomyopathy was more common in middle aged and elderly population. Males were more commonly affected than females. Dysponea was the commonest symptom followed by fatiguability. The most common ECG abnormality was sinus tathycardia followed by ventricular ectopic. Commonest presentation was ischaemic cardiomyopathy (40\%) followed by idiopathic DCMP (28\%), diabetic cardiomyopathy (20\%) and peripartum cardiomyopathy (8\%).

Conclusion: DCMP is a commonly encountered clinical entity in heart failure patients. Ischemic cardiomyopathy (ICMP) is the commonest among all DCMP patients followed by idiopathic dilated cardiomyopathy. Biventricular failure was the commonest presentation and commonest ECG abnormalities were sinus tachycardia and ventricular ectopics.

Keywords: Dilated cardiomyopathy (DCMP), ischemia cardiomyopathy (ICMP), left ventricular ejection fraction $(L V E F)$. 


\section{Introduction}

Dilated cardiomyopathy includes a group of heterogenous myocardial disorders characterized by ventricular dilation and depressed myocardial contractility in the absence of abnormal loading conditions like hypertension and valvular heart disease. Dilated cardiomyopathy is the end results of myocardial dysfunction due to various aetiological causes like ischaemic insult, toxics, metabolic causes damaging the heart muscle directly. The protean manifestations of dilated cardiomyopathy are heart failure, arrhythmias, cardioembolic stroke and sudden death, the former being the commonest. Dilated cardiomyopathy accounts for $25 \%$ of all causes of heart failure. The incidence of DCMP is about 5-8 per 1 lakh population per year. Males are affected three times more commonly than females. The clinical characteristics and cardiomyopathy are well described. ${ }^{1-3}$ however, the incidence, aetiology and prognosis of DCMP may differ among patients with different socioeconomic and geographic locations. The prevalence of DCMP in Japan is about half of the western population and in Africa and latin America it is twice as common as compared to the Western counterpart. ${ }^{1}$ Symptomatic heart failures patients of DCMP have progressive deterioration with $50 \%$ succumbing within one year. Dilated cardiomyopathy is no more a diagnosis by exclusion in view of rapid advancement in investigation like molecular genetics.

\section{Aims \& Objectives}

The present study was undertaken to study the clinical presentation, electrocardiographic changes, echocardiographic parameters and to establish the etiology of dilated cardiomyopathy in patients of heart failure admitted to department of Cardiology of SCB Medical College \& Hospital over a period of one year.

\section{Material \& Methods}

This is a prospective cross sectional observational study involving fifty (50) patients of dilated cardiomyopathy admitted to department of Cardiology of SCB Medical College \& Hospital, Cuttack, Odisha over a period of one year.

\section{Inclusion Criteria}

- Symptoms of heart failure

- Left ventricular end diastolic dimension (LVEDD) $>3.0 \mathrm{~cm} / \mathrm{m}^{2}$

- Global hypokinesia of LV with/ without $\mathrm{RV}$ involvement

- LVEF $<40 \%$

\section{Exclusion Criteria}

- Congenital heart disease

- Valvular heart disease

- Hypertension

- Pericardial disease

Total no. of 50 patients were taken for the present study. After admission to the hospital detailed clinical examination, routine blood investigations like FBS, Urea, Creatinine, Electrolytes, Liver function test, $\mathrm{HbA} 1 \mathrm{C}$ were done. ECG, X-Ray chest PA view and Echocardiography were done.

\section{Results}

In our study, total no of fifty patients of heart failure due to DCMP were included males were 32 in number and females 18 in number. The male: female ratio was 1.7:1 (Table I).

Table-I: Sex of Study Population

\begin{tabular}{|l|c|c|}
\hline & Number & Percentage (\%) \\
\hline Male & 32 & $64 \%$ \\
\hline Females & 18 & $36 \%$ \\
\hline
\end{tabular}

In our study, the commonest mode of presentation was breathlessness (100\%) followed by fatiguability $(80 \%)$. Other symptoms were PND $(60 \%)$, orthopneoa $(52 \%)$ and palpitation $(44 \%)$ (Table II).

\section{Table-II: Symptoms complex profile}

\begin{tabular}{|l|c|c|}
\hline Symptoms & Number & Percentage (\%) \\
\hline Dyspnoea & 50 & $100 \%$ \\
\hline Orthopnoea & 26 & $52 \%$ \\
\hline PND & 30 & $60 \%$ \\
\hline Fatiguability & 40 & $80 \%$ \\
\hline Pedal Oedema & 32 & $64 \%$ \\
\hline Chest Pain & 18 & $36 \%$ \\
\hline Palpitation & 22 & $44 \%$ \\
\hline Syncope & 8 & $16 \%$ \\
\hline
\end{tabular}


Majority of patients were symptomatic NYHA class III (48\%) and class IV (32\%) (Table-III).

\section{Table- III}

\begin{tabular}{|l|c|c|}
\hline NYHA Class & Number & Percentage \\
\hline Class I & 2 & $4 \%$ \\
\hline Class II & 8 & $16 \%$ \\
\hline Class III & 24 & $48 \%$ \\
\hline Class IV & 16 & $32 \%$ \\
\hline
\end{tabular}

Biventricular failure $(76 \%)$ was most common followed by LVF (20\%), only two (4\%) patients presented with RV failure (Table-IV).

Table-IV: Heart Failure

\begin{tabular}{|l|c|c|}
\hline Type of HF & Number & Percentage \\
\hline Biventricular & 38 & $76 \%$ \\
\hline LVF & 10 & $20 \%$ \\
\hline RVF & 2 & $4 \%$ \\
\hline
\end{tabular}

Chest radiography revealed cardiomegaly in all patients. Electrocardiography was abnormal in all fifty patients. Commonest ECG abnormality was sinus tachycardia (44\%) followed by ventricular ectopics (40\%) and LBBB (36\%). Atrial fibrillation was presents in $20 \%$ of cases. Complete heart block (CHB) was percent only in one $(2 \%)$ patient. Left ventricular hypertrophy (LVH) \& Right ventricular hypertrophy (RVH) were presents in $15(30 \%)$ \& $4(8 \%)$ cases respectively. Atrial enlargement like left atrial enlargement (LAE) \& right atrial enlargement (RAE) were present in $16(32 \%) \& 5(10 \%)$ cases respectively (Table-V).

Table-V: ECG Characteristics

\begin{tabular}{|l|c|c|}
\hline Type & Number & Percentage \\
\hline LAE & 16 & $32 \%$ \\
\hline RAE & 5 & $10 \%$ \\
\hline LVH & 15 & $30 \%$ \\
\hline RVH & 4 & $8 \%$ \\
\hline Both & 2 & $4 \%$ \\
\hline Sinus trachycardia & 22 & $44 \%$ \\
\hline Supraventricular ectopics & 6 & $12 \%$ \\
\hline Atrial fibrillation & 10 & $20 \%$ \\
\hline Ventricular ectopics & 20 & $40 \%$ \\
\hline Ventricular tachycardia & 2 & $4 \%$ \\
\hline CHB & 1 & $2 \%$ \\
\hline LBBB & 18 & $36 \%$ \\
\hline RBBB & 8 & $16 \%$ \\
\hline
\end{tabular}

Echocardiography abnormalities like increased LV end diastolic dimension \& reduced ejection fraction with presence of mitral regurgitation
(MR) were commonly found. The mean LVEDD was $5.48 \mathrm{~cm}$. Global hypokinesia was seen in all patients. The mean LVEF was $31.25 \%$ \& LVEF of less than $20 \%$ was found in $4(8 \%)$ patients (Table-VI).

Table-VI: Echocardiographic abnormalities

\begin{tabular}{|c|c|c|}
\hline Parameter & Number & Percentage \\
\hline LVEF 30-40\% & 26 & $52 \%$ \\
$20-29 \%$ & 20 & $40 \%$ \\
$<20 \%$ & 4 & $8 \%$ \\
\hline LVEDD 4.5-4.9 (cm) & 8 & $16 \%$ \\
$5.0-5.9(\mathrm{~cm})$ & 22 & $44 \%$ \\
& 20 & $40 \%$ \\
\hline MR $>6.0(\mathrm{~cm})$ & 40 & $80 \%$ \\
\hline TR & 10 & $20 \%$ \\
\hline Pericardial effusion (PE) & 6 & $12 \%$ \\
\hline
\end{tabular}

\section{Discussion}

The present study was aimed at evaluation of clinical presentation, ECG and echocardiographic abnormalities and to determine the aetiology of dilated cardiomyopathy in fifty patients admitted to a tertiary care hospital of state of Odisha. In our study the mean age of presentation in males and females were $55.58 \pm 14.89$ years and $40.5 \pm 18.75$ years respectively. In our study breathlessness $(100 \%)$ was the most common symptoms. Majority of there were symptomatic NYHA class III $(48 \%) \&$ class IV (32\%). Similarly orthopnoea $\&$ PND were seen in $52 \%$ \& $60 \%$ of patients. Fatiguability and pedal oedema were present in $80 \% \& 64 \%$ of patients respectively. This is agreement with the study done by Singh $\mathrm{G}$ et $\mathrm{al}^{4}$ and Jain $\mathrm{A}$ et $\mathrm{al}^{5}$. In our study the commonest ECG findings was sinus tachycardia similar to study by $\mathrm{S}$. Ahmed et $\mathrm{al}^{6}$. LVH was present in $30 \%$ of patients in our study which is similar to other studies. Chest radiography showed cardiomegaly in all patients which is similar in study by Mausmi et $\mathrm{al}^{7}$. Echocardiographically the mean LVEF of $31.25 \%$ in our study was similar to that of Divakar et $\mathrm{al}^{5}$. The mean LV end diastolic and systolic diameter. In our study were similar to other studies. The incidence of MR (80\%) as compared TR (20\%) was more common in our study as ischaemic cardiomyopathy was the common cause of DCM in our study population. 


\section{Conclusion}

Dilated cardiomyopathy is the commonest cardiomyopathy \& is an important cause of heart failure in day to day clinical practice. It is commonly seen in middle aged \& elderly population through all age group individuals are prone to suffer from this. Peripartum cardiomyopathy is commonly seen in young age and various aetiological agents also do cause cardiomyopathy in young population. Ischaemic cardiomyopathy was more common in males where in diabetic and idiopathic DCM were more common in females. ECG abnormalities like sinus tachycardia, LBBB, AF and LAE in sinus rhythm in patients of heart failure of short duration i.e. few days to weeks gives a clinical clue to the diagnosis of dilated cardiomyopathy. Echocardiography establishes the diagnosis by showing global hypokinesia of dilated left ventricle with or without RV dilation with grossly reduced systolic function. Other echocardiographic findings like LAE, MR, TR, pericardial effusion may be present. Hence, a diligent clinical history, physical examination, ECG changes \& finally echocardiography establishes the diagnosis of dilated cardiomyopathy in patients of heart failure. Further work up with advanced technology is likely to establish the aetiology of cardiomyopathy.

\section{References}

1. Richardson. WHO Report on classification of cardiomyopathy Br. Heart J. 1980; 44: 680-682.

2. Framingham Heart Study nih. Gov/Framingham.

3. Braunwald and Briston MR. Congestive heart failure: Fifty year of progress. Circulation 2000; 102;14.

4. Singh G, Nyyan SB. Clinical profile of dilated cardiomyopathy $-\mathrm{A}$ study of 138 cases , JAPI 2002:502:1156.
5. Jain A, Tewari S clinical profile of dilated cardiomyopathy, Indian Heart J 2004;56:507-17.

6. Ahmed S, Rabbani M, Zaheer M, Shirazi N. Clinical ECG and Echocardiographic profile of patients with dilated cardiomyopathy. Indian $\mathbf{J}$ Cardiol 2005;8:25-9.

7. Maaumi RA, Jorge CR. Primary myocardial disease. Report of 50 cases and review of the subject. Circulation 1965;312:19-40. 